\title{
Application of Information and Communication Technology (ICT) in Administration of Physical Education and Sports
}

\author{
Dr. Ben Ohuruogu \\ Ebonyi State University, Abakaliki. \\ Ugwu Jude Ikechukwu \\ Ebonyi State University, Abakaliki \\ Dr. Eneka Mong \\ Ebonyi State University, Abakaliki. \\ Alor Roseline Chinyere
}

Physical and Health Education Department Ebonyi State College Of Education, Ikwo

\begin{abstract}
The paper focused on application of information and communication technology (ICT) in the administration of physical education and sports. Information and communication technology was seen on the convergence of audiovisual and telephone networks with computer networks which covers any product that will store, retrieve, manipulate, transmit and receive digital information. This facility was shown to be very useful in the administration of physical education and sports. The device enhances communication of information in the administration of physical education and sports. It also enhances experience in dance and dance education, and provides feedback that make teachers evaluate success in the programme and make students work harder. The paper saw ICT hardware and software as veritable tool for teaching physical education and simplifying data collection and analysis. The paper concluded that ICT represents one of the most useful tools for enhancing the decoding of physical education and sports curriculum if used correctly, and therefore recommended that proper practical ICT training should be provided for physical education teachers and student in schools and colleges by the ministry of science and education.
\end{abstract}

Keywords: Physical Education, Computer, ICT and Sports

DOI: $10.7176 / \mathrm{JEP} / 10-24-01$

Publication date: August 31st 2019

\section{Introduction}

This decade is characterized by rapid technological advances. Being in the digital era, technology has accounted for many changes in the educational sector. These changes range from the method instruction is delivered to the attitudes on how learning occurs to the amount of collaboration and knowledge sharing between not only students, but also between teachers, managers and administrators. ICT represents one of the most and useful tools to enhance curriculum if used correctly. According to (Passey Rosers, Machell \& Michuga 2004), teaching and learning with technology has had a significant impact on students outcomes when compared to traditional instruction.

Physical Education and Sports have undergone technological changes in recent time. Technology had an impact in learning in general education, could it also enhance teaching and learning in PE and Sports? New developments in the field of technology will positively affect the physical, education curriculum for example, the use of technological advances will prepare physical, educators for the future demands and expectations of the society. Furthermore, the Ministry of Education is laying much emphasis on integrating ICT in the teaching and learning process in schools. As students perform exercises and skills in their PE, Classes, PE Teachers can use technological tools and systems to quantify processes and results to help them learn more about themselves. (Van. Damme 2001). However, before using ICT in our schools as a teaching tool, these important questions must be addressed? What technological options are available for our physical educators? Do using technological tools in the PE classes motivate the students? What is the role of technology as an assessment tool how it is linked to performance?

In order to enhance the learning and performance, the use of ICT is widely used in modern world. The field of PE and sports is not left behind while making the use of various latest ICT tools. The role of information, communication and technology (ICT) has been widely used in the recent past throughout the world. Therefore, the use of ICT, along with other changes, seems to be immense in modern era. However, in Nigeria, despite the huge potential offered by ICT, their actual use seems to confined to only elite institutions and sports persons'.

Today, ICT tools helps in improving efficiency and performance of Nigeria sports at international level. Rankings the competitiveness and well being of any nation at international level in various economic, social, educational and other parameters, sports performances of that country also makes a huge contribution in its overall 
performance. Therefore being a sports super power in global order is what we Nigerians aspire for.

In order to compete with advance sports countries, we try to do all possible things to improve the performance of our Nigerian Sports persons. We bring changes in our training methods, schedules and take help of various training and teaching aids to improve the sports performance;

\section{Concepts of Administration, Sports and ICT}

Administration: Administration as the part of management is concerned with the installation and carrying out of the procedures by which programmes, plans and targets are laid down and communicated, and the progress of activities regulated and checked against them (Mbipom 2001). According to Ukeje, Akaburogu and Ndu (1992) administration and management are taken to be same and between educational administration and educational management, the two are often used interchangeably. They maintained that administrations is an activity that maintains organizations their reciprocal purposes may be attained.

Sports: Bucher and Krotee (1998) defined sports as competitive activities with strict rules and regulations, bounded by space and time and are often serious business.

Abone (2002) defined sports as dynamic social forces, institutionalized physical activities, usually requiring the demonstration of physical activities. In this work sports are regarded as those competitive activities, which has rules and regulations which one does for pleasure and with physical efforts or skills.

Information and Communication Technology (ICT): Information and Communication Technology is often used as an extended synonym for information technology (IT). ICT refer to the convergence of audio-visual and telephone networks with computer networks through a single cabling or link system: Infact, ICT covers any product that will store, retrieve, manipulate, transmit or receive information electronically in a digital form, ICT is the digital processing and Utilization of information by the use of electronic computers. It comprises the storage, retrieval, conversion and transmission of information (Okauru 2011).

Infact ICT is an umbrella term that includes any communication device or application en-compassing, radio, television, cellular phones, computer and network hardware and software, satellite system and so on as well as the various services and applications associated with them, such as video conferencing and distance learning. ICT are often spoken of in a particular context, such as ICT in education, health care, libraries (Rouses, 2005).

The term information and communication technologies ICT refers to forms of technologies that are used to create, store, share or transmit exchange information. This includes such technologies like radio, television, video, DVD, telephone (both fixed line and mobiles phones), satelliete systems, computer and network hardware and software, as will as the equipment and services associated with these technologies, such as video conferencing and electronic mail, (British Education and Technology Association BECTa 2002).

\section{Various ICT Considered for use in Physical Education and sports}

i. Pedometers: These apparatus also called step counters are mechanical sensors used to count steps and can easily be incorporated in physical education and sports classes. They address motivation, assessment, and advocacy. Furthermore, they are portable and can be worn under the belt and be kept the whole day. Today, it can be said that the pedometer has become a recognized, acceptable tool for measuring physical activity. Students can wear a pedometer and receive immediate and continuous feedback regarding their activity level; (Bailey 2001). Using pedometers at school can also demonstrate to parents that students are achieving a certain level of physical activity. By using the pedometers, students will be able to see progress towards set goal and consequently will be more motivated in the classes.

ii. Heart Rate Monitors: Based completely on the student ability level and current level of fitness, the heart rate monitor makes learning more student centered. It also provides immediate feedback that can make student work harder, (Beashel \& Sibson 2000). Boyer. As fitness level increases, student feel that their cardio-vascular system is working and can set individualized goal to work more effectively.

iii. Digital Video Camera and Visual Analysis Software: The use of the motion analysis system will surely enhance many areas of physical education curriculum both in research and teaching. Using digital video camera has indeed simplified the collection of data. These results can then be imported to carry out interactive multimedia presentation to provide students with a better understanding of the importance of breaking skills into components and the consequences of subtle variation in techniques (Capel 2004). The visual analysis software allows students to view captured movement and to analysis them. Thus particular technology can help teachers to control student's progress towards motor skills goals, provide feedback opportunities and assessing students learning. Digital video camera are also used to international Journal of Applied, Research, record pupils performance in table tennis. Example are its useful as a tool to help students improve their techniques. With the addition of motion analysis software, pupils have a professional supportive tool.

iv. Simulation and Games: Games such as Dance, dance revolution, fx cycles and Nintendo Wii fit provide opportunities for students to be physically active and simultaneously enjoying themselves. These games can 
also be combined to other technologies to enhance the experience (Green Well 2003). Concerning the Nintendo Wii fit, works outs are done on a small balanced board that games stand on. The players receive instructions from screen and mimic the stretching and muscle building exercises. The Wii Fit tracking feature shows progress using the system. Therefore, it can be a valuable physical education tool. However, teachers should not consider gaining system equivalent to traditional exercises. It should be considered as a supplement and a not a replacement of traditional exercises.

v. Internet: A global network providing the capability to communicate, share ideas and access information and resources from around the globe. Intranet similar to internet, but information from within a school or organization CD-ROM information is presented in the form of graphics and text with sound and moving video Data handling information can be stored in a database. Desktop publishing a combination of text, graphics and layout to produce a document. Examples are presentation software displaying information in slide form.

The following ICT applications can be used in physical education and sports.

Cameras: Video cameras can provide footage of experienced performers in action and can be used in inspire, to demonstrate correct techniques and to develop pupil's understanding and knowledge of the subject. By receiving their own actions for example, pupils can evaluate and improve their own games strategies, gymnastics sequences, trampolining routines or dance compositions, particularity if they are able to look at their performance in slow motion or from a different viewing angle.

Mobile Camera Phones: The use of mobile phones in schools is a contentious issue. Some schools may allow students to use their mobile phone within P.E lessons. For example; during an orienteering unit of work students can take photographs with their phones of the items they were trying to find and use the picture as evidence of completion of the course pupils can also set up their own orienteering courses; using their pictures taken with their phones and transferred to the computers within the lesson, other groups can then have the opportunity to attempt various different courses which could be an excellent way to integrate ICT and literacy into PE. Thus could especially work well if there is minimal ICT equipment within the department.

Motion Analysis Software: The use of motion analysis software within PE is becoming a more mainstream means of evaluating pupil performance and enhancing learning. There are many software packages available; software such as "dartfish" can provide pupils with visual images of their performances that can be slowed down but also enlarged. This allows teachers, using a digital camera, to split the screen into progressive frames and is therefore useful for highlighting techniques in some of the athletic field events or trampolining routines. Freeze-framing and overlay facilities are also a useful application. The footage can be saved and stored for moderation purposes. Whilst there are certain advantages in using this type of software there also some disadvantages.

Film Editing in Physical Education and Sports: Video footage taken in one lesson can be edited and used at the beginning of the following lesson to highlight the achievement of students but also to identify common faults. This enables teachers and students to study individual and team performance across a range of activities. Teachers and students can compile footage from all the different lessons and use the footage to show other pupils in different classes what to expect using film-editing software packages that teachers can use to support and enhance teaching and training in PE and sports. One package is the film-editing software package movie which allows users to edit their own video footage. Movie imports video footage using a fire wire interface on most min, DVD format digital video cameras. From there, the user, can edit the video clips, add titles and add music.

Portable Multimedia Player: Portable multimedia players (PMP), some times referred to as a portable video player (PVP) or an internet media Tablet (IMT), are capable of storing and playing digital media. Digital, Audio players (DAP) that can also display images and play videos are portable multimedia players. Like DAPS, the data is typically stored on a hard drive. Micro drive or flash memory, other types of electronic devices like mobile phones are sometimes referred as PMPs because of their play back capabilities.

\section{Benefits of Using ICT in P.E and Sports}

i. Video cameras and video analysis software are useful for analyzing, assessing and improving performance. Like delay programmes provides immediate feedback to individuals and groups enabling them to identify areas for development and acquire and develop skill, using analysis packages to compare students perform area with the model performance, enables students to evaluate and improve perform once; using producer packages to develop teaching cards and reciprocal coaching cards, allows students to take on different responsibilities in class, develop skills and select appropriate skills to suit the situation.

ii. Power point for presentation and demonstration of students' ability to select and synthesis information to meet their needs and develop an ability question its accuracy, bias and plausibility and to exchange and share information. For example, challenges can be set on a power point presentation from which students select an appropriate one for their ability/needs; diverse information can be provided from which students must select an appropriate solution to a problem set. Power point can be used to conduct plenary sessions and also used as a tool for assessing learning. 
iii. The use of internet helps to find resources to support teaching. The use of websites can extend students learning and help with the setting of enrichment activities, students can use websites to find things out, develop ideas, exchange and share information, whilst reviewing, modifying and evaluating work as it progress.

iv. Heart rate monitors and other health related exercise equipment to develop students knowledge and understanding of what happens to their body airing exercise, improve their ability to estimate the effects of exercise on their body and to develop appropriate training methods for different activities.

v. The use of interactive CD ROMS and DVDs that enable students to learn new skills or develop existing skills through visual and auditory demonstrations. Use of these media enable video/audio demonstrations of skills played in full or broken down into components; or they can provide interactive peer evaluation sheets which can be used on interactive white board to focus students attention on improving and evaluating their and others work; some CD ROMS provide game plans, which help students select and apply skills and tactical ideas using animated drill or game play plans; fitness and health CD ROMS that enable students' to develop their knowledge and understanding of fitness and health by selecting generic or sports specific warm-ups, understanding components of fitness and developing and understanding of the effects of exercise on the body.

vi. ICT also helps in administration and record keeping and it saves times which could be enjoyable and is instrumental in career development.

vii. ICT also makes lesson class more interesting especially as it has potential within P.E and sports trading in general.

- $\quad$ The use of ICT also help address learning objectives, increases students motivation which later improve their performance.

- $\quad$ The use of ICT has made competition judging easier and more accurate, and spectator interest and excitement is enhanced by broadcasting and in-stadium displays (scone boards).

- $\quad$ ICT in PE and sports makes the science of sport come to life by linking both physical and mental activity. It also helps to create full-fledged students who are able to concentrate better on both practical and theoretical work. Besides, it helps students to develop a better understating of their own body parts and that of the human body in general.

\section{Challenges on the use of ICT in PE and Sports}

The following are some of the challenges according to

- $\quad$ Lack of trained personnel to handle some ICT equipments and resources

- $\quad$ Lack of fund to purchase the required ICT equipment and resources to be used in teaching and learning PE and Sports.

- Power shortage. Some ICT equipment resources requires power for its operation and there is insufficient power to cater for that

- An acicte shortage of ICT resources and equipment, particularly in relation to the specific needs of the subject areas; some trainers who subsequently went to well equipped schools were therefore not familiar with euquipment they needed to be able to use in schools, whilst those who had few (or no) resources in their placement schools completed the course with insufficient ICT experience. Some additional equipment was on site was not fully operational.

\section{Summary and Conclusions}

This decade is characterized $\mathrm{b}$ rapid technological advances. Being in the digital era,, technology has accounted for man changes in the educational sector. These changes range from the method instruction is delivered, to the attitudes on how learning occurs to the amount of collaboration and knowledge. ICT represents one of the most useful tools for enhances curriculum delining if used correctly. Through ICT tools, students can benefit from immediate feedback to improve their observational and analysis skills. As they familiarizes with the software, they are able also to point out the relevant points for positive technique: The main advantage, however, remain the general improvement in the performance level of the majority of the students work, as they struggle their way to look impressive especially if their performance will be analyzed on digital video system.

\section{Recommendations}

The following recommendations were made:

- Proper training should be provided to teachers and students in relation to the use of ICT tools through workshops, seminars or other courses by the education authority.

- $\quad$ Specific equipments like digital video camera and visual analysis software should be provided to the physical education department in all school by the ministry of education

- $\quad$ Parent Teachers Association (PTA) and other sponsors should contribute to raise funds to buy equipments for ICT in schools.

- Internet facilities should be given to both teachers and students by it school authority for good communication 
between department, between teachers and students to modern up to date technologies related to rules and regulations of sports.

- Students should be authorized to use their mobile phones with camera options to view their own or others' performances while performing a particular skill by the school authorities. This can also help practionize learning of PE and sports.

\section{References}

Abone, M. (2002). Professionalization of sport, administration and Management in Nigeria. Any benefit. Nigeria Association of Physical Education, Recreation, Sports, and Dance. Journal JONAPHER SD: 2(1)

Bailey., R. (2001). Teaching physical Education: A Handbook for primary and secondary teachers. (London, Kogan Page).

Beashel, P \& Sibson, A. (2000). ICT-help or hindrance? British Journal of Teaching Physical Education, 31 (2). Pp. 6-8.

British Education and Technology Association (BECTa) (2000) Impact 2: The Impact of information and Communication Technologies on student learning and Attainment. (London, Hmso).

Bucher, C.A and Krotee; M. L (1998). Management OF Physical Education and sports. New York: Mc Graw Hill.

Capel, S. (2004). Learning to teach physical Education in the Secondary School. A companion to school experience (London, Routledge).

Greenwell, E. (2003). Physical Education: An Interactive approach, Sports teacher. Currently available at http://www.sportsteacher co.uk/news/editorial/pehtml, accessed 17.11.04.

Mbipom, C. (2001). Resource Acquisition and Management for effective Administration of U.B. E. ESUT Journal of Education 4 (3) 26-36.

Okauru, (2011). Retrieved, from http://www.college. Assignments wordpress.com.

Passey, D. Rogers. C; Machell; J. \& Mchugh; J (2004). The Motivational Effects of ICT on students. Report RR 523, (London, DFES).

Rouse, M. (2005). Retrieved from http://www.collegeassignmetwordpress.com.

Ukeje, B.O. Akabuogu, Gu. And Ndu; A. (1992). Educational Administration. Enugu Fourth Dimension Publishing Company Ltd.

Van Damme G. (2001). The new Physical Education and Sports Discussion. Accessed from http:www.sportsmedia.org/sport a polisnews letters 5. htm 17. 11.14. 